International Journal of Medical Sciences

ISSN 1449-1907 www.medsci.org 2006 3(2):47-52

Review

(C)2006 Ivyspring International Publisher. All rights reserved

\title{
The Natural History of Hepatitis C Virus (HCV) Infection
}

\author{
Stephen L. Chen ${ }^{12}$ and Timothy R. Morgan ${ }^{12}$ \\ 1. Gastroenterology Section, VA Medical Center, Long Beach, California \\ 2. Division of Gastroenterology and Hepatology, University of California-Irvine, Irvine, California
}

Corresponding address: Timothy R. Morgan, MD, VA Long Beach Healthcare System, 5901 East Seventh Street, Long Beach, California 90822. E-mail: timothy.morgan@med.va.gov. FAX:(562) 826-8023

Received: 2005.12.30; Accepted: 2006.03.06; Published: 2006.04.01

Hepatitis $\mathrm{C}$ virus (HCV) is a leading cause of chronic liver disease, cirrhosis, and hepatocellular carcinoma, as well as the most common indication for liver transplantation in many countries. Although the incidence of hepatitis $\mathrm{C}$ infection has dramatically decreased during the past decade, the worldwide reservoir of chronically infected persons is estimated at 170 million, or $3 \%$ of the global population. There is much controversy surrounding the natural history of hepatitis C infection. The rate of chronic HCV infection is affected by a person's age, gender, race, and viral immune response. Approximately $75 \%-85 \%$ of $\mathrm{HCV}$-infected persons will progress to chronic $\mathrm{HCV}$ infection, and are at risk for the development of extrahepatic manifestations, compensated and decompensated cirrhosis, and hepatocellular carcinoma (HCC). The rate of progression to cirrhosis is highly variable, and is influenced by several factors, including the amount of alcohol consumption, age of initial HCV infection, degree of inflammation and fibrosis on liver biopsy, HIV and HBV coinfection, and comordid conditions. An estimated 10\%-15\% of HCV-infected persons will advance to cirrhosis within the first 20 years. Persons with cirrhosis are at increased risk of developing HCC. An understanding of the natural history of hepatitis $C$ is essential to effectively manage, treat, and counsel individuals with HCV infection.

Key words: Natural history, acute, chronic, hepatitis C, liver fibrosis, cirrhosis, hepatocellular carcinoma, HCV, HCC

\section{Introduction}

Chronic hepatitis $C$ is the most common cause of chronic liver disease and cirrhosis, and the most common indication for liver transplantation in the United States (U.S.), Australia, and most of Europe.[1-3] Approximately 170 million people are affected with $\mathrm{HCV}$ worldwide, comprising $\sim 3 \%$ of the global population.[4] Hepatitis C virus $(\mathrm{HCV})$ is the most common chronic bloodborne infection in the U.S., and is involved in $40 \%$ of chronic liver disease.[4, 5] HCV was initially isolated from the serum of a person with non-A, non-B hepatitis in 1989 by Choo et al.[6] Shortly after the cloning of HCV, this newfound virus was discovered to be the cause of approximately $90 \%$ of non-A, non-B hepatitis in the U.S.

The hepatitis $C$ virus is an RNA virus that belongs to the family flaviviridae.[7] HCV replicates in the cytoplasm of hepatocytes, but is not directly cytopathic. Persistent infection appears to rely on rapid production of virus and continuous cell-to-cell spread, along with a lack of vigorous $\mathrm{T}$-cell immune response to $\mathrm{HCV}$ antigens. The $\mathrm{HCV}$ turnover rate can be quite high with replication ranging between $10^{10}$ to $10^{12}$ virions per day, and a predicted viral half-life of 2 to 3 hours.[8] The rapid viral replication and lack of error proofreading by the viral RNA polymerase are reasons why the HCV RNA genome mutates frequently.[9] There are six known genotypes (numbered 1 through 6) and more than 50 subtypes (e.g., 1a, 1b, 2a...).[4] Frequent HCV mutations and numerous subtypes have made the search for an $\mathrm{HCV}$ vaccine challenging.

There is strong evidence demonstrating the association of chronic HCV infection to cirrhosis and hepatocellular carcinoma (HCC). $\mathrm{HCV}$ is a mounting global health challenge, causing a significant proportion of chronic liver disease around the world. In understanding the long-term outcomes of HCV infection, clinicians may identify the patients at risk for HCV-related complications, and offer treatments to prevent further morbidity and mortality.

\section{Routes of Transmission}

The transmission of $\mathrm{HCV}$ is primarily through exposure to infected blood. Risks for transmission include blood transfusion before 1992, intravenous drug use, highrisk sexual activity, solid organ transplantation from an infected donor, occupational exposure, hemodialysis, household exposure, birth to an infected mother, and intranasal cocaine use. According to the U.S. Centers for Disease Control and Prevention (CDC), the most common risk factors for acute HCV infection in the U.S. from 19911995 were high-risk drug $(60 \%)$ and sexual behaviors $(20 \%)$. Other modes of transmission (occupational, hemodialysis, household, and perinatal) accounted for approximately $10 \%$ of infections. A potential risk factor can be identified in approximately $90 \%$ of persons with $\mathrm{HCV}$ infection. In the remaining $10 \%$, no recognized source of infection can be identified, although most persons in this category are associated with low socioeconomic level.[2] With current screening methods, $\mathrm{HCV}$ transmission through transfusion of contaminated blood products is approximately 1 in 500,000 to 2,000,000 transfusions.[10-12]

\section{Acute Hepatitis $\mathrm{C}$}

In the U.S., the incidence of acute hepatitis $C$ was estimated to be 180,000 cases per year in the mid-1980s (peak incidence), but declined to approximately 30,000 new cases per year in 1995.[13] The incidence of acute hepatitis C infection in the U.S. declined sharply in 1990, possibly because of needle exchange programs and greater awareness of high risk HIV behavior.[5] Acute hepatitis $C$ infection is infrequently diagnosed because the majority of acutely infected individuals are asymptomatic. 
In the transfusion setting, where acute onset of $\mathrm{HCV}$ infection has been best documented, $70 \%$ to $80 \%$ of cases were asymptomatic.[14] About $20 \%$ to $30 \%$ of adults with acute $\mathrm{HCV}$ infection may develop clinical symptoms. The symptomatic onset ranges from 3 to 12 weeks after exposure.[15, 16] Symptoms may include malaise, weakness, anorexia, and jaundice. Serum alanine aminotransferase (ALT) levels, signifying hepatocyte necrosis, begin rising 2 to 8 weeks after exposure, and often reach levels of greater than 10 times the upper limits of normal. HCV RNA can be detected in the serum within 1 to 2 weeks after exposure.[16, 17] The level of HCV RNA rises rapidly during the first few weeks, and then peaks between $10^{5}$ to $10^{7} \mathrm{IU} / \mathrm{ml}$, shortly before the peak of serum aminotransferase levels and onset of symptoms. In self-limited acute hepatitis $C$, symptoms can last several weeks and subside as ALT and HCV RNA levels decline. Acute $\mathrm{HCV}$ infection can be severe, but fulminant liver failure is rare.[18]

The antibody to $\mathrm{HCV}$, as detected by enzyme immunoassay, becomes positive near the onset of symptoms, approximately 1 to 3 months after exposure. $\mathrm{Up}$ to $30 \%$ of patients will test negative for anti-HCV at onset of their symptoms, making anti-HCV testing unreliable in diagnosis of acute infection.[17] Almost all patients eventually develop the antibody to HCV; however, titers can be low or undetectable in immunodeficient patients. The anti-HCV assay detects greater than $90 \%$ of $\mathrm{HCV}$ infections after the initial 3 months.

\section{Chronic Hepatitis $\mathrm{C}$}

Chronic hepatitis $C$ is marked by the persistence of HCV RNA in the blood for at least 6 months after onset of acute infection. HCV is self-limiting in only $15 \%-25 \%$ of patients in whom HCV RNA in the serum becomes undetectable and ALT levels return to normal. Approximately $75 \%-85 \%$ of infected patients do not clear the virus by 6 months, and chronic hepatitis develops. The rate of chronic HCV infection is affected by many factors, including the age at time of infection, gender, ethnicity, and the development of jaundice during the acute infection (see Table 1).

Table 1. Risk Factors for Developing Chronic HCV Infection

\begin{tabular}{|c|}
\hline Risk Factors \\
\hline Age at time of infection $>25$ years \\
\hline Male gender \\
\hline No jaundice or symptoms during acute infection \\
\hline African American race \\
\hline HIV infection \\
\hline Immunosuppression \\
\hline
\end{tabular}

\section{Age at Time of Infection}

The chronicity rate in hepatitis $\mathrm{C}$ infection appears to be lower in younger individuals. The most widely quoted data on the prevalence of HCV in the United States comes from the third National Health and Nutrition Examination Survey (NHANES), a national survey of a representative sample of non-institutionalized civilian Americans conducted between 1988 and 1994. In the NHANES study, the chronicity rate was estimated at $30 \%$ in subjects below the age of 20 years, and $76 \%$ for those older than 20 years.[13] Long term follow-up studies in children with post-transfusion hepatitis indicate that only $55 \%$ to $60 \%$ of children remain HCV RNA positive in adulthood.[19] Studies of vertical transmission from mother to infant have suggested that a sizeable proportion of infants have transient infection and then clear the HCV RNA, sometimes without ever producing HCV antibodies.[20] In the Dionysos study from Italy, residents between the ages of 12 and 25 years had a chronicity rate of $56 \%$, compared with $87 \%$ for those above the age of 25 years.[21] The current data suggests that persons with $\mathrm{HCV}$ infection at younger age, less than 25 years, are less likely to have chronic hepatitis $\mathrm{C}$ than those infected at older ages.

\section{Gender}

The rate of chronicity in $\mathrm{HCV}$ infection appears to be lower in women, particularly younger women. Evidence for this comes mostly from retrospective analyses of two large outbreaks of hepatitis $\mathrm{C}$ that occurred among pregnant women who received $\mathrm{Rh}$ immune globulin that had been contaminated with HCV. In a 17-year follow-up study of 704 Irish women with anti-HCV after receipt of contaminated immune globulin, the chronicity rate was 55\%.[22] The same HCV chronicity rate $(55 \%)$ was found in a 20-year follow-up study of 917 German women who had received a similarly $\mathrm{HCV}$ contaminated $\mathrm{Rh}$ immune globulin.[23] Conversely, large cross-sectional studies have not demonstrated gender differences in the rate of chronicity in hepatitis C infection. The NHANES[13] study and the Dionysos study[21] had similar rates of HCV chronicity among both men and women.

\section{Race}

There are differences in the rate of chronic $\mathrm{HCV}$ infection, response to treatment, and development of complications, among different racial and ethnic groups with HCV infection. For unclear reasons, African Americans appear to have a higher rate of chronic HCV infection than Caucasians and Hispanic whites. In prospective surveys among inner-city Baltimore (Maryland, U.S.) injection drug users, the prevalence of chronic HCV infection in African American men was 95\%.[24, 25] The NHANES study also revealed a higher rate of chronic infection among African Americans (86\%), compared to Caucasians (68\%) $(\mathrm{p}=0.02)$. In addition, African American had a lower rate of sustained viral response (SVR) to interferon and ribavirin treatment for $\mathrm{HCV}$ infection.[26] Interestingly, African Americans and Asians with HCV have a 2-fold and 4-fold increased risk, respectively, of developing HCC when compared to Caucasians with HCV.[27] No host or viral genetic differences have yet been identified to explain the racial disparities in the incidence of chronic $\mathrm{HCV}$, response to treatment, or development of HCC. Clinical trials are currently ongoing in the U.S. to identify these factors.

\section{Jaundice and Immune Response}

The rate of chronic HCV infection is lower in patients who develop jaundice or symptoms during the acute onset of $\mathrm{HCV}$ infection as compared to those who are anicteric. In a prospective study of $142 \mathrm{HCV}$-infected subjects with a history of illicit drug use, subjects with viral clearance were more likely to have symptoms of jaundice $(p=0.03)$. [25] Furthermore, the long-term followup study of women infected with contaminated Rh immune globulin in Germany exhibited a rate of chronicity in $43 \%$ of those with history of jaundice, as compared to $60 \%$ among those who remained anicteric $(p<0.001)$. Many have speculated that the jaundice may be associated with a more robust immune Th1 lymphocyte 
and cytokine response to the HCV.[28, 29] The competency of the immune response plays a significant role in the development of chronic hepatitis $C$, as well as the progression of liver fibrosis. The rates of chronic HCV infection developing in patients with human immunodeficiency virus (HIV) infection and CD4 < 200, have been higher than in patients without HIV infection.[30]

\section{Progression of Liver Fibrosis}

In the setting of persistent hepatitis $C$ viremia, the rate of progression of liver fibrosis varies widely. There have been extensive studies focusing on the natural course of disease progression from chronic hepatitis $\mathrm{C}$ to cirrhosis, HCC, and death. The liver biopsy is the gold standard for the grading and staging of chronic hepatitis C. The activity of liver disease or grade, is gauged by the number of mononuclear inflammatory cells present in and around the portal areas, and by the number of dead or dying hepatocytes. The structural liver damage, also known as fibrosis or stage, is variable in chronic HCV infection. Fibrosis implies possible progression to cirrhosis. In mild cases, fibrosis is limited to the portal and periportal areas. More advanced changes are defined by fibrosis that extends from one portal area to another, also known as "bridging fibrosis."

Cirrhosis develops in approximately $10 \%$ to $15 \%$ of individuals with chronic HCV infection.[4] There are external and host factors that can increase the risk of progression of liver disease (see Table 2). Multiple studies have shown that chronic alcohol use is a major external risk factor for the progression of chronic hepatitis $\mathrm{C}$ to cirrhosis and HCC. Host risk factors include older age at time of infection, male gender, the degree of inflammation and fibrosis present on the liver biopsy, coinfection with human immunodeficiency virus (HIV) or hepatitis B virus (HBV), and comorbid conditions such as immunosuppression, insulin resistance, non-alcoholic steatohepatitis, hemochromatosis, and schistosomiasis.

Table 2. Risk Factors for Advanced Progression of Liver Fibrosis

\begin{tabular}{|c|}
\hline Risk Factors \\
\hline Alcohol consumption ( $>30 \mathrm{~g} /$ day in males, $>20$ \\
\hline $\mathrm{g} /$ day in females) \\
\hline Age at time of infection $>40$ years \\
Male gender \\
\hline Degree of inflammation and fibrosis on liver \\
\hline biopsy \\
\hline Coinfection with HIV or HBV \\
\hline Comorbid disease \\
\hline
\end{tabular}

\section{Alcohol consumption}

Alcohol consumption appears to be one of the most influential factors driving fibrosis progression in patients with chronic hepatitis $C$. There is convincing evidence that higher levels of alcohol consumption contributes to the development of progressive liver disease.[31-38] Individuals who consume alcohol as an ongoing habit have a greater prevalence of cirrhosis than those who consume little or no alcohol. The 2002 United States National Institutes of Health (NIH) Consensus Statement reports detrimental effects of $30 \mathrm{~g} /$ day in men (roughly equivalent to 3-4 12-ounce beers, 3-4 4-ounce glasses of wine, or 3 shots of a mixed drinks) and $20 \mathrm{~g} /$ day in women.[4] Lower amounts of daily alcohol consumption may also increase the risk of $\mathrm{HCV}$-associated liver damage.

\section{Age at Time of Infection}

Several studies have shown a significant association between the rate of fibrosis and the age at time of infection.[38, 39] After controlling for the estimated duration of HCV infection, the stage of fibrosis was significantly higher in patients that were infected at an older age ( $>40$ years), than those infected at younger ages.[38] The degree of inflammation and fibrosis on the liver biopsy has also been associated with further progression of HCV liver disease.[40] This data suggests that the progression of liver fibrosis in $\mathrm{HCV}$ infection is non-linear, and may develop at a faster rate as the patient ages.

\section{Coinfection with HIV and HBV}

HCV coinfections with HIV or HBV are significant risk factors for liver fibrosis. Coinfection with $\mathrm{HCV}$ and HIV is particularly common among hemophiliacs and injection drug users. HIV seropositivity and low CD4 count appears to accelerate HCV liver fibrosis.[41-43] Conversely, HCV has been associated with a faster progression of HIV to acquired immunodeficiency syndrome (AIDS).[44] Similarly, HCV coinfection with HBV also exhibits higher rates of progression to cirrhosis.

\section{Comorbid Conditions}

The role of comorbid conditions and HCV infection is an important component in the natural history of HCV infection. Immunosuppression has been associated with more aggressive liver disease. Patients with humoral immunoglobulin deficiency (hypogammaglobulinemic) or cellular immune impairment (organ transplant recipients) have shown significantly higher rates of progression to cirrhosis than immunocompetent patients.[42, 45, 46] Insulin resistance appears to be associated with worsening liver fibrosis and decreased response to HCV therapy.[4750] The relationship between HCV infection and comorbid conditions, such as non-alcoholic steatohepatitis, obesity, and insulin resistance are discussed in further detail in this issue of IJMS.

\section{Long Term Complications \\ Cirrhosis and HCC}

The progression to cirrhosis is often clinically silent, and some patients are not known to have hepatitis $C$ until they present with the complications of end-stage liver disease or HCC. The features of decompensated cirrhosis include the development of ascites, upper gastrointestinal bleeding secondary to varices or portal hypertensive gastropathy, hepatorenal syndrome and hepatic encephalopathy. In the U.S., deaths associated with chronic $\mathrm{HCV}$ are more likely to be caused from decompensated cirrhosis rather than HCC. Studies have estimated the 3, 5, and 10-year survival rates of compensated cirrhosis to be $96 \%, 91 \%$, and $79 \%$, respectively.[51]. The cumulative probability of an episode of clinical decompensation is $5 \%$ at 1 year, and increases to $30 \%$ at 10 years from the diagnosis of cirrhosis.[51-53] Once decompensated cirrhosis occurs, the 5 -year survival rate falls to $50 \%$.[51] The time from HCV infection to cirrhosis is dependent on multiple factors, and cannot be predicted in an individual patient. Virtually all HCV-related HCC occurs among patients with cirrhosis. In a meta-analysis of 21 case-control studies, the risk for 
HCC was increased 17-fold in HCV-infected patients compared to HCV-negative controls.[54] The results of several retrospective trials show a moderate decrease in the risk of developing HCC among HCV patients treated with interferon.[55-58] This benefit appears to be greater in patients with a sustained viral response rather than non-responders to interferon treatment.[59]

Multiple studies have attempted to measure the time interval from infection to cirrhosis and HCC. Frequently, the initial time of infection is not known, and therefore must be estimated. On the other hand, individuals that contracted $\mathrm{HCV}$ through a single blood transfusion or surgery are able to provide more precise time intervals from infection to cirrhosis and HCC. In a longitudinal U.S. study by Tong et al., the mean time of development of cirrhosis was $21+/-10$ years in chronic post-transfusion hepatitis $C$ patients.[60] Although the mean time to cirrhosis in chronic HCV patients is estimated at 20 years, only $10-20 \%$ of patients will actually develop cirrhosis within this time period.[4, 61] In this same study by Tong et al., the time to diagnosis of HCC was $28+/-11$ years.[60] In a European study by Castells et al., the time to development of cirrhosis and HCC was 24 years and 27 years, respectively.[62] Once cirrhosis is established, HCC develops at an annual rate of $1 \%$ to $4 \%$.[52, 56, 57, 63-66] Higher estimates in the range of $5-7 \%$ have been reported from Japan. Given the close time range between cirrhosis and HCC, it is imperative to screen for HCC in HCV patients with cirrhosis. In the U.S., Australia, and Europe, liver transplantation is the principle long-term treatment for patients with severely decompensated cirrhosis and/or hepatocellular carcinoma.[3]

\section{Extrahepatic Manifestations}

Chronic HCV infection has been associated with numerous extrahepatic manifestations. These manifestations can involve multiple organ systems, including renal, dermatologic, hematologic, and rheumatologic systems.[67, 68] Approximately 1\%-2\% of $\mathrm{HCV}$-infected individuals will develop extrahepatic manifestations. The most common extrahepatic condition is mixed cryoglobulinemia. Cryoglobulins are found in $50 \%$ of patients with chronic HCV infection. Cryoglobulinemia was found to be 11 times more frequent in a veterans $\mathrm{HCV}$ cohort group than their respective control population.[68] Only $25 \%-30 \%$ of $\mathrm{HCV}$ patients with mixed cryoglobulinemia develop clinical symptoms, ranging from fatigue, skin rashes, purpura, arthralgias, Raynaud's phenomenon, vasculitis, renal disease, and peripheral neuropathies.[69] The clinical manifestations are thought to be caused by immune complex deposition in various organs. Severe symptoms from cryoglobulinemia appear to respond to interferon treatment, but relapse occurs frequently once treatment is discontinued.[70]

Other frequent extrahepatic manifestations found in patient with chronic $\mathrm{HCV}$ infection are membranoproliferative glomerulonephritis, porphyria cutaneous tarda, lichen planus, and vitiligo. There is also some data that suggests an association between chronic HCV infection and non-Hodgkin's and Hodgkin's lymphoma, autoimmune thyroditis, Sjogren's syndrome, and seronegative arthritis. It is unclear if these associated diseases are caused directly from HCV infection or from the underlying immune stimulation caused by chronic infection.

\section{Summary}

The chronic nature of hepatitis $\mathrm{C}$ infection influences the clinical approach and management of this disease. Prevention of the HCV infection is possible by understanding the various mechanisms of viral transmission. Acute $\mathrm{HCV}$ infection is difficult to diagnose since $70 \%-80 \%$ of infected individuals are asymptomatic. Most infected persons are unaware of their exposure to $\mathrm{HCV}$, and do not get diagnosed until many years later. The rate of chronic HCV infection is affected by the person's age at time of infection, gender, race, and viral immune response. A large proportion of $\mathrm{HCV}$-infected persons, ranging from $75 \%-85 \%$, develop chronic $\mathrm{HCV}$ infection, and are at risk for advanced liver fibrosis, HCVrelated extrahepatic complications, cirrhosis and HCC (see Figure 1). The rates of liver fibrosis progression is highly variable, and is influenced by the amount of alcohol consumption, age of initial HCV infection, degree of inflammation and fibrosis on liver biopsy, HIV or HBV coinfection, and comordid conditions. An estimated 10\%$20 \%$ of chronic HCV infections advance to end-stage liver disease over one or two decades. Extrahepatic manifestations can occur during chronic $\mathrm{HCV}$ infection or cirrhosis, but HCC appears to develop only after cirrhosis is established. Research is ongoing to determine the histological, biochemical, genetic and demographic markers that may further predict the outcome of $\mathrm{HCV}$ infections.

Figure 1. Natural History of HCV Infection

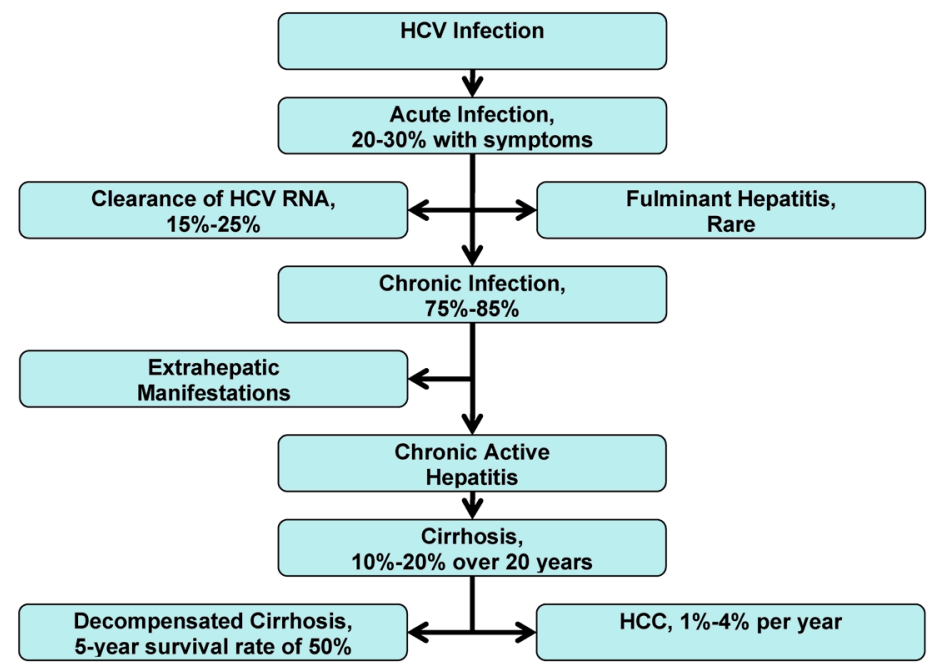

\section{Future Research Direction}

There is a need for further research on HCV and the risk factors that lead to progression of fibrosis, cirrhosis, and HCC. Identification of additional viral, host, and external factors would help in developing means of prevention, early detection, and treatment. Although, many studies have examined the clinical course of HCV infection, long-term cohort studies are still needed to characterize the risk factor profiles that may predict the eventual outcome in chronic HCV infection, and to further define the outcome of patients with greater than 30 years of HCV infection. Since the response rates to our current $\mathrm{HCV}$ therapies are still variable, there is a necessity for innovative new therapies and vaccines. Importantly, our HCC screening and surveillance methods need to be evaluated to determine if they are effective in reducing morbidity and mortality in patients with cirrhosis. 


\section{Abbreviations}

AIDS: acquired immunodeficiency syndrome; ALT: alanine aminotransferase; CDC: United States Centers for Disease Control; HBV: hepatitis B virus; HCV: hepatitis C virus; HCC: hepatocellular carcinoma; HIV: human immunodeficiency virus; NASH: non-alcoholic steatohepatitis; NHANES: United States National Health and Nutrition Examination Survey; NIH: United States National Institutes of Health; RNA: ribonucleic acid.

\section{Conflict of Interest}

None

\section{References}

1. Wasley A and Alter M.J. Epidemiology of hepatitis C: geographic differences and temporal trends. Semin Liver Dis, 2000. 20(1): 1-16.

2. Alter M.J. The epidemiology of acute and chronic hepatitis C. Clin Liver Dis, 1997. 1(3): 559-68.

3. Charlton M. Hepatitis C infection in liver transplantation. Am J Transplant, 2001. 1(3): 197-203.

4. [No authors listed]. National Institutes of Health Consensus Development Conference Statement: Management of hepatitis C 2002 (June 10-12, 2002). Gastroenterology, 2002. 123(6): 2082-99.

5. Centers for Disease Control and Prevention. Recommendations for prevention and control of hepatitis C virus (HCV) infection and HCV-related chronic disease. MMWR Recomm Rep, 1998. 47: 1-39.

6. Choo Q.L, et al. Isolation of a cDNA clone derived from a bloodborne non-A, non-B viral hepatitis genome. Science, 1989. 244(4902): 359-62.

7. Lauer G.M and Walker B.D. Hepatitis C virus infection. N Engl J Med, 2001. 345(1): 41-52.

8. Neumann $\mathrm{AU}$, et al. Hepatitis $\mathrm{C}$ viral dynamics in vivo and the antiviral efficacy of interferon-alpha therapy. Science, 1998. 282(5386): 103-7.

9. Bukh J, Miller R.H., and Purcell R.H. Genetic heterogeneity of hepatitis C virus: quasispecies and genotypes. Semin Liver Dis, 1995. 15(1): 41-63.

10. Dodd R.Y, Notari E.P.t., and Stramer S.L. Current prevalence and incidence of infectious disease markers and estimated windowperiod risk in the American Red Cross blood donor population. Transfusion, 2002. 42(8): 975-9.

11. Roth W.K, et al. Yield of HCV and HIV-1 NAT after screening of 3.6 million blood donations in central Europe. Transfusion, 2002. 42(7): 862-8.

12. Schreiber G.B, et al. The risk of transfusion-transmitted viral infections. The Retrovirus Epidemiology Donor Study. N Engl J Med, 1996. 334(26): 1685-90.

13. Alter M.J, et al. The prevalence of hepatitis $C$ virus infection in the United States, 1988 through 1994. N Engl J Med, 1999. 341(8): 556-62.

14. McCaughan G.W, et al. Clinical assessment and incidence of hepatitis C RNA in 50 consecutive RIBA-positive volunteer blood donors. Med J Aust, 1992. 157(4): 231-3.

15. Alter H.J and Seeff L.B. Recovery, persistence, and sequelae in hepatitis $C$ virus infection: a perspective on long-term outcome. Semin Liver Dis, 2000. 20(1): 17-35.

16. Thimme R, et al. Determinants of viral clearance and persistence during acute hepatitis C virus infection. J Exp Med, 2001. 194(10): 1395-406.

17. Farci $P$, et al. A long-term study of hepatitis $C$ virus replication in non-A, non-B hepatitis. N Engl J Med, 1991. 325(2): 98-104.

18. Farci $P$, et al. Hepatitis $C$ virus-associated fulminant hepatic failure. N Engl J Med, 1996. 335(9): 631-4.

19. Vogt M, et al. Prevalence and clinical outcome of hepatitis C infection in children who underwent cardiac surgery before the implementation of blood-donor screening. N Engl J Med, 1999. 341(12): 866-70.

20. Sasaki N, et al. Loss of circulating hepatitis $C$ virus in children who developed a persistent carrier state after mother-to-baby transmission. Pediatr Res, 1997. 42(3): 263-7.
21. Bellentani $S$ and Tiribelli C. The spectrum of liver disease in the general population: lesson from the Dionysos study. J Hepatol, 2001. 35(4): 531-7.

22. Kenny-Walsh E. Clinical outcomes after hepatitis C infection from contaminated anti-D immune globulin. Irish Hepatology Research Group. N Engl J Med, 1999. 340(16): 1228-33.

23. Wiese $M$, et al. Low frequency of cirrhosis in a hepatitis $C$ (genotype 1b) single-source outbreak in germany: a 20-year multicenter study. Hepatology, 2000. 32(1): 91-6.

24. Seeff L.B, et al. Long-term mortality and morbidity of transfusionassociated non-A, non-B, and type $C$ hepatitis: A National Heart, Lung, and Blood Institute collaborative study. Hepatology, 2001. 33(2): 455-63.

25. Villano S.A, et al. Persistence of viremia and the importance of longterm follow-up after acute hepatitis C infection. Hepatology, 1999. 29(3): 908-14.

26. Howell C, Jeffers L., and Hoofnagle J.H. Hepatitis C in African Americans: summary of a workshop. Gastroenterology, 2000. 119(5): 1385-96.

27. Nguyen M.H, et al. Role of ethnicity in risk for hepatocellular carcinoma in patients with chronic hepatitis $\mathrm{C}$ and cirrhosis. Clin Gastroenterol Hepatol, 2004. 2(9): 820-4.

28. Gruner N.H, et al. Association of hepatitis C virus-specific CD8+ T cells with viral clearance in acute hepatitis C. J Infect Dis, 2000. 181(5): 1528-36.

29. Lechner F, et al. Analysis of successful immune responses in persons infected with hepatitis C virus. J Exp Med, 2000. 191(9): 1499-512.

30. Thomas D.L, et al. The natural history of hepatitis $C$ virus infection: host, viral, and environmental factors. Jama, 2000. 284(4): 450-6.

31. Wiley T.E, et al. Impact of alcohol on the histological and clinical progression of hepatitis C infection. Hepatology, 1998. 28(3): 805-9.

32. Noda $K$, et al. Progression of type $C$ chronic hepatitis to liver cirrhosis and hepatocellular carcinoma--its relationship to alcohol drinking and the age of transfusion. Alcohol Clin Exp Res, 1996. 20(1 Suppl): 95A-100A.

33. Ostapowicz G, et al. Role of alcohol in the progression of liver disease caused by hepatitis C virus infection. Hepatology, 1998. 27(6): 1730-5.

34. Peters M.G and Terrault N.A. Alcohol use and hepatitis C. Hepatology, 2002. 36(5 Suppl 1): S220-5.

35. Pessione F, et al. Effect of alcohol consumption on serum hepatitis $\mathrm{C}$ virus RNA and histological lesions in chronic hepatitis C. Hepatology, 1998. 27(6): 1717-22.

36. Corrao $G$ and Arico S. Independent and combined action of hepatitis $C$ virus infection and alcohol consumption on the risk of symptomatic liver cirrhosis. Hepatology, 1998. 27(4): 914-9.

37. Harris D.R, et al. The relationship of acute transfusion-associated hepatitis to the development of cirrhosis in the presence of alcohol abuse. Ann Intern Med, 2001. 134(2): 120-4.

38. Poynard T, Bedossa P., and Opolon P. Natural history of liver fibrosis progression in patients with chronic hepatitis $\mathrm{C}$. The OBSVIRC, METAVIR, CLINIVIR, and DOSVIRC groups. Lancet, 1997. 349(9055): 825-32.

39. Ryder S.D, et al. Progression of hepatic fibrosis in patients with hepatitis C: a prospective repeat liver biopsy study. Gut, 2004. 53(3): 451-5.

40. Yano $\mathrm{M}$, et al. The long-term pathological evolution of chronic hepatitis C. Hepatology, 1996. 23(6): 1334-40.

41. Ragni M.V and Belle S.H. Impact of human immunodeficiency virus infection on progression to end-stage liver disease in individuals with hemophilia and hepatitis C virus infection. J Infect Dis, 2001. 183(7): 1112-5.

42. Benhamou $\mathrm{Y}$, et al. Liver fibrosis progression in human immunodeficiency virus and hepatitis $C$ virus coinfected patients. The Multivirc Group. Hepatology, 1999. 30(4): 1054-8.

43. Di Martino $\mathrm{V}$, et al. The influence of human immunodeficiency virus coinfection on chronic hepatitis $\mathrm{C}$ in injection drug users: a long-term retrospective cohort study. Hepatology, 2001. 34(6): 1193-9.

44. Lesens $\mathrm{O}$, et al. Hepatitis $\mathrm{C}$ virus is related to progressive liver disease in human immunodeficiency virus-positive hemophiliacs and should be treated as an opportunistic infection. J Infect Dis, 1999. 179(5): 1254-8. 
45. Bjoro $\mathrm{K}$, et al. Hepatitis $\mathrm{C}$ infection in patients with primary hypogammaglobulinemia after treatment with contaminated immune globulin. N Engl J Med, 1994. 331(24): 1607-11.

46. Berenguer $\mathrm{M}$, et al. HCV-related fibrosis progression following liver transplantation: increase in recent years. J Hepatol, 2000. 32(4): 67384 .

47. D'Souza R, Sabin C.A., and Foster G.R. Insulin resistance plays a significant role in liver fibrosis in chronic hepatitis $C$ and in the response to antiviral therapy. Am J Gastroenterol, 2005. 100(7): 150915.

48. Fartoux L, et al. Insulin resistance is a cause of steatosis and fibrosis progression in chronic hepatitis C. Gut, 2005. 54(7): 1003-8.

49. Romero-Gomez $\mathrm{M}$, et al. Insulin resistance impairs sustained response rate to peginterferon plus ribavirin in chronic hepatitis $\mathrm{C}$ patients. Gastroenterology, 2005. 128(3): 636-41.

50. Muzzi A, et al. Insulin resistance is associated with liver fibrosis in non-diabetic chronic hepatitis C patients. J Hepatol, 2005. 42(1): 41-6.

51. Fattovich G, et al. Morbidity and mortality in compensated cirrhosis type C: a retrospective follow-up study of 384 patients. Gastroenterology, 1997. 112(2): 463-72.

52. Serfaty L, et al. Determinants of outcome of compensated hepatitis $C$ virus-related cirrhosis. Hepatology, 1998. 27(5): 1435-40.

53. Hu K.Q and Tong M.J. The long-term outcomes of patients with compensated hepatitis C virus-related cirrhosis and history of parenteral exposure in the United States. Hepatology, 1999. 29(4): 1311-6.

54. Donato F, Boffetta P., and Puoti M. A meta-analysis of epidemiological studies on the combined effect of hepatitis B and C virus infections in causing hepatocellular carcinoma. Int J Cancer, 1998. 75(3): 347-54.

55. Ikeda K, et al. Effect of interferon therapy on hepatocellular carcinogenesis in patients with chronic hepatitis type C: A long-term observation study of 1,643 patients using statistical bias correction with proportional hazard analysis. Hepatology, 1999. 29(4): 1124-30.

56. Fattovich G, et al. Occurrence of hepatocellular carcinoma and decompensation in western European patients with cirrhosis type B. The EUROHEP Study Group on Hepatitis B Virus and Cirrhosis. Hepatology, 1995. 21(1): 77-82.

57. Nishiguchi S, et al. Randomised trial of effects of interferon-alpha on incidence of hepatocellular carcinoma in chronic active hepatitis $\mathrm{C}$ with cirrhosis. Lancet, 1995. 346(8982): 1051-5.

58. International Interferon-alpha Hepatocellular Carcinoma Study Group. Effect of interferon-alpha on progression of cirrhosis to hepatocellular carcinoma: a retrospective cohort study. Lancet, 1998. 351(9115): 1535-9.

59. Papatheodoridis G.V, Papadimitropoulos V.C., and Hadziyannis S.J. Effect of interferon therapy on the development of hepatocellular carcinoma in patients with hepatitis $C$ virus-related cirrhosis: a metaanalysis. Aliment Pharmacol Ther, 2001. 15(5): 689-98.

60. Tong M.J, et al. Clinical outcomes after transfusion-associated hepatitis C. N Engl J Med, 1995. 332(22): 1463-6.

61. Seeff L.B. Natural history of chronic hepatitis C. Hepatology, 2002. 36(5 Suppl 1): S35-46.

62. Castells L, et al. Long interval between HCV infection and development of hepatocellular carcinoma. Liver, 1995. 15(3): 159-63.

63. Gordon S.C, Bayati N., and Silverman A.L. Clinical outcome of hepatitis C as a function of mode of transmission. Hepatology, 1998. 28(2): 562-7.

64. Degos F, et al. Hepatitis $C$ virus related cirrhosis: time to occurrence of hepatocellular carcinoma and death. Gut, 2000. 47(1): 131-6.

65. Chiba T, et al. Multivariate analysis of risk factors for hepatocellular carcinoma in patients with hepatitis $\mathrm{C}$ virus-related liver cirrhosis. J Gastroenterol, 1996. 31(4): 552-8.

66. Bruno $S$, et al. Hepatitis $C$ virus genotypes and risk of hepatocellular carcinoma in cirrhosis: a prospective study. Hepatology, 1997. 25(3): 754-8.

67. Gumber S.C and Chopra S. Hepatitis C: a multifaceted disease. Review of extrahepatic manifestations. Ann Intern Med, 1995. 123(8): 615-20.

68. El-Serag H.B, et al. Extrahepatic manifestations of hepatitis $\mathrm{C}$ among United States male veterans. Hepatology, 2002. 36(6): 1439-45.
69. Cacoub P, et al. Extrahepatic manifestations associated with hepatitis $C$ virus infection. A prospective multicenter study of 321 patients. The GERMIVIC. Groupe d'Etude et de Recherche en Medecine Interne et Maladies Infectieuses sur le Virus de l'Hepatite C. Medicine (Baltimore), 2000. 79(1): 47-56.

70. Lunel $\mathrm{F}$ and Cacoub P. Treatment of autoimmune and extrahepatic manifestations of hepatitis C virus infection. J Hepatol, 1999. 31 (Suppl 1): 210-6.

\section{Author biography}

Stephen L. Chen, MD, is a fellow in the Division of Gastroenterology and Hepatology, University of California-Irvine, Irvine, California USA. His clinical interests include natural history and management of hepatitis B and C.

Timothy R. Morgan, MD, is the Chief of Hepatology, Gastroenterology Section, Long Beach VA Medical Center, Long Beach, California. His research interests are in hepatitis $\mathrm{C}$ and alcoholic liver disease. 